\title{
Morphological variations in the basioccipital region of the South Indian skull
}

\author{
Ray $B^{1}$, Kalthur $S G^{2}$, Kumar $B^{2}$, Bhat MR $K^{2}$, D'souza $A S^{2}$, Gulati $H S^{2}, K N L K^{2}, V S B^{3}$
}

\section{${ }^{1}$ Department of Anatomy, All India Institute of Medical Science, Bhopal, Madhya Pradesh, ${ }^{2}$ Department of Anatomy, Kasturba Medical College, ${ }^{3}$ Department of Statistics, Manipal University,Manipal, Karnataka}

\section{*Corresponding Author:}

Dr. Sneha Guruprasad Kalthur, Associate Professor Department of Anatomy, Kasturba Medical College Manipal University, Manipal- 576104

Karnataka, India

E-mail: sneha.guruprasad@manipal.edu

\begin{abstract}
Background: The craniovertebral junction is a transitional region of spine that exhibits extensive structural variability. Variations of basiocciput are of interest for anatomists and clinicians because they produce clinical symptoms or lead to misinterpretations of radiological images.
\end{abstract}

Materials and Methods: The study was conducted on 202 dry human skull bone (12 occipital bone and crania 190) belonging to south Indian population for variations of basiocciput over a period of six years..

Results: Prevalence of hyperostotic variants was significantly higher than hypostotic variants in present study. Most common type observed was of precondylar tubercle (2.48\%) followed by fossa navicularis (1.49). The prevalence of other variations such as prebasioccipital arch, third occipital condyle, exostosis and basioccipital cleft was similar $(0.5 \%)$ in the study population.

Conclusions: These cranio-vertebral anomalies will be useful not only to anatomists, radiologists and surgeons while dealing with base of the skull and basiocciput in particular but also to study anthropological significance and may guide the future researchers in comparative human anatomy.

Key words - Occipital bone, basiocciput, foramen magnum, occipital condyles

\section{Introduction:}

Basiocciput is the portion of occipital bone that extends anteriorly from anterior rim of foramen magnum and fuses with sphenoid bone. ${ }^{1}$ Occipital bone is a major site of variations because it is a part of "ontogenically restless and unstable" craniovertebral junction. ${ }^{2}$ The occipital vertebra is formed form the most caudal four calvarialsclerotomes and the proatlas is derived from cranial half of first cervical sclerotome. In humans the proatlas merges with the occiput. Variation in development of proatlas leads to various malformations. If the proatlas gets incompletely assimilated into the occiput,it leads to various expressions of occipital vertebra and on other hand if normal segmentation fails to occur, it results inatlantooccipital fusion. ${ }^{3}$

The human cranium shows wide variety of variations with respect to age, gender, race and geographical distribution. Osseous variants in basiocciput regions have been reported earlier. The most commonly reported variations are precondylar tubercle ${ }^{4}$, third occipital condyle and prebasioccipital $\operatorname{arch}^{5}$, exostosis or tubercle on the anterior margin of foramen magnum ${ }^{6}$, fossa navicularis ${ }^{7}$ and basioccipital cleft. ${ }^{3}$ The detection and diagnosis of these craniovertebral anomalies are essential as many of them produce symptoms like transient quadriparesis and even death $^{8}$ or may lead to misinterpretations during diagnosis by radiological methods.Apart from their clinical significance they are of importance in anthropological and ethnological studies. In the present study we analyzed the prevalence of morphological variations in basiocciput regions of south Indian skull.

\section{Materials and methods:}

The present study was conducted over a period of six years on 202 bones. The study group comprised of undamaged 190 
dry human crania and 12 occipital bones. The basiocciputal region of crania and occipital bones were examined for morphological variations and classified into following types.

A. Hyperostotic variety: This group included variations such as precondylar tubercle, prebasioccipital arch, third occipital condyle and exostosis on anterior margin of foramen magnum.

B. Hypostatic variety: This group included variations such as basioccipital cleft and fossa navicularis.

The variations were assessed and represented as percentage of prevalence.

\section{Results:}

In the present study out of 202 skull bones of south Indian population, $12(5.9 \%)$ had variations in the basiocciputregion. Among these 12 skull bones with variations, 11 were observed in crania and one in occipital bone. The prevalence of hyperostotic variation was 3.96\% (8 out 202 bones) and was significantly higher $(\mathrm{p}<0.05)$ than the hypostatic variations (1.98\%). We found precondylar tubercle in $2.48 \%$, third occipital condyle in $0.5 \%$, exostosis on anterior margin of foramen magnum in $0.5 \%$, basioccipital cleft in $0.5 \%$ and fossa navicularis in $1.49 \%$ bones (Figure 1 ).

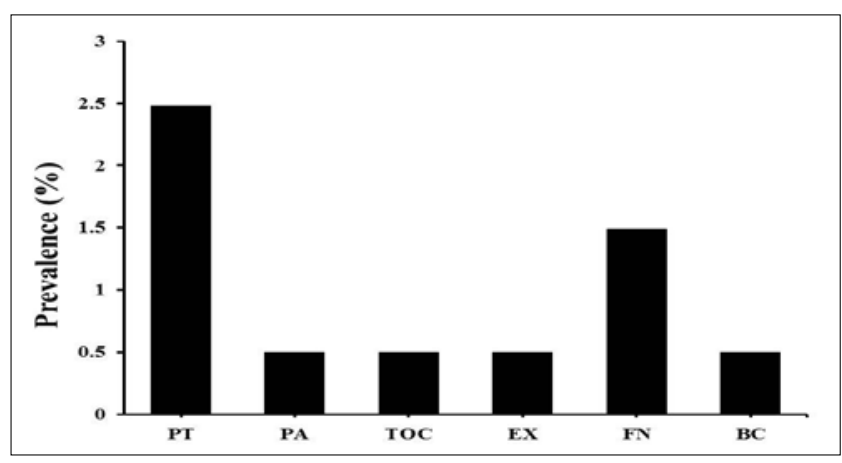

Figure 1: Graph showing prevalence of different nonmetrical variations inbasiocciput

PT: Precondylar tubercle; PA:Preoccipital arch; TOC: Third occipital condyle; EX:Exostosis; FN: Fossa navicularis; $B C:$ Basioccipital cleft

Further, in hyperostatic type of basiocciputs, the most common variation was precondylar tubercle [5 out of 202 $(2.48 \%)]$. Out of the 5 precondylar tubercle, one was in the midline and the remaining 4 were observed in paramedian position. When these precondylar tubercle were further classified as described by Vasudev et al ${ }^{4}$, one each were of type I (ridges- Fig. 2A -I) and type II (spine- Fig.2AII), three precondylar tubercle were found to be of type III (process, Fig.2A- III).

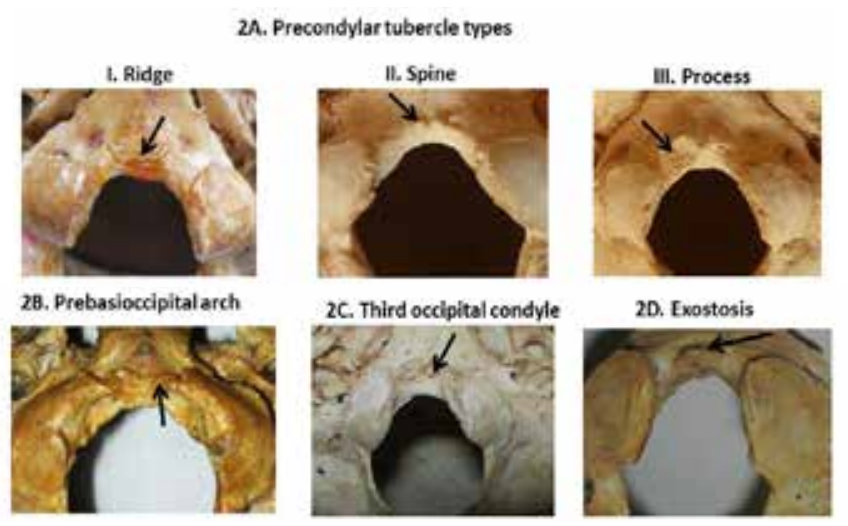

Figure 2: Photographs showing various Hyperostotic variants in South Indian skull: a-Ridge shaped precondylar tubercle on basiocciput; b- Spine shaped precondylar tubercles on basiocciput; c. Photograph showing processlike precondylar tubercle on basiocciput; $d$-Prebasioccipital arch; e-Third occipital condyle; f-Bony exostosis pointing downwards from anterior margin of foramen magnum.

In prebasioccipital arch variety one skull $(0.5 \%)$ showed complete arch (Fig.2B) which was projected as a horizontal thickening immediately in front of foramen magnum. Thickness of these bony bridges varied as it was $6 \mathrm{~mm}$ on left side and $4 \mathrm{~mm}$ on right side. Presence of third occipital condyle is rare and one skull $(0.5 \%)$ showed an articular third occipital condyle (Fig.2C) which was attached to anterior margin of occipital condyles measuring $2 \times 2 \mathrm{~mm}$ in dimension. The prevalence of exostosis on anterior margin of foramen magnum was low observed in onlyone of the occipital bone $(0.5 \%)$. This projection measured $3 \mathrm{~mm}$ vertically, $2 \mathrm{~mm}$ antero-posteriorly and $6 \mathrm{~mm}$ width (Fig.2D).

Under hypostotic variety, fossanavicularis type was observed in 3 out of 202 skull bones $(1.49 \%)$. Its mean length was $5 \mathrm{~mm}$ and mean width was $3.66 \mathrm{~mm}$. Depth of the fossa navicularis was greater than $0.5 \mathrm{~mm}$ in one skull and lesser than $0.5 \mathrm{~mm}$ in other 2 skulls. Distance between fossa navicularis and anterior limit of anterior margin of foramen magnum was $19.33 \mathrm{~mm}$ (Fig.3a). One skull bone had basioccipital cleft $(0.5 \%)$. The bilateral clefts extended from the lateral border of inferior aspect of basiocciput (Fig.3b).
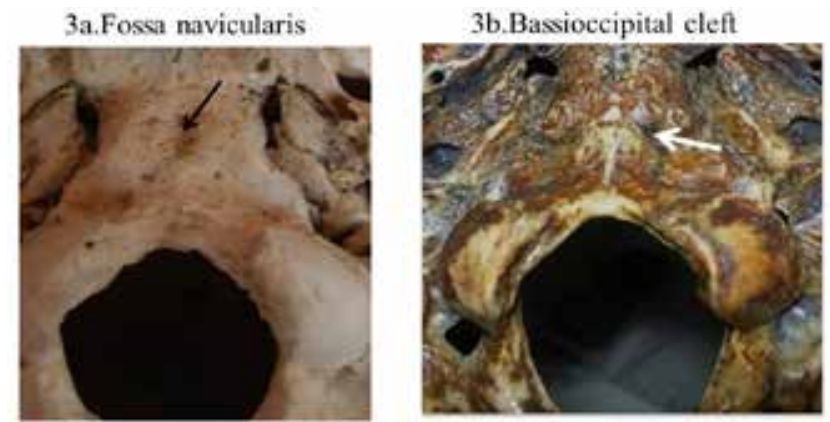

Figure 3. Photograph showing various Hypostotic variants 
in South Indian skull: a-Fossa navicularis (indicated by arrow head); b-Basioccipital cleft (indicated by arrow head).

Distance of this cleft from the anterior margin of foramen magnum was $3.75 \mathrm{~mm}$. Each groove was $2 \mathrm{~mm}$ length transversely on both sides.

\section{Discussion}

Anatomists remained curious about minor variations of cranium, e.g. ossicles, foramina and ridges for many decades. In the present study, we have observed an array of variations in basiocciput of South Indian skulls and occipital bones $(5.45 \%)$ which was compared with other authors (Table 1). The cranial bone variations could be due to the maternal environment ${ }^{9}$, or genetic variation or adaptation to environment including postnatal stress factors. ${ }^{10}$ Absence or presence of minor cranial variation can be related to sex, age and weight of skeleton. ${ }^{11}$ This kind of diversity of discrete cranial traits in modern humans may be due to retention of ancestral pattern or result of the process of population differentiation. ${ }^{10,12}$

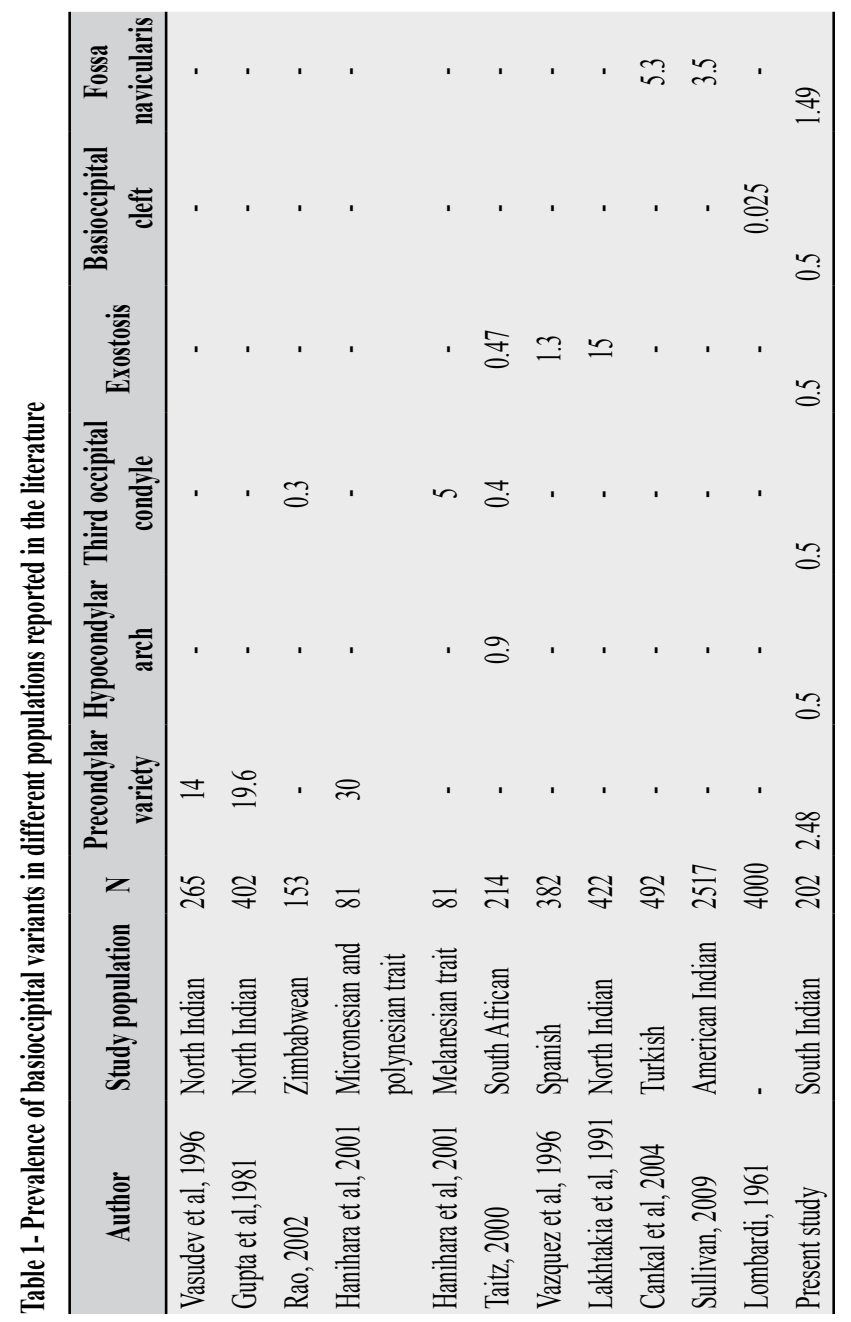

Hyperostotic traits are believed to be as age- progressive changes and more frequently on left side and hypostatic traits are age-regressive changes. ${ }^{9}$ Thus, statically significant differences between prevalence of hyperostotic (3.96\%) and hypostotic (1.98\%) variants found in our study may be due to the availability of old aged unclaimed bodies in India.

The precondylar process also known as basilar processes mamillar or papillar processes are hemisphere-shaped bone projections located at the front rim of the occipital foramen magnum with high degree of variance. The frequency of precondylar process is reported to be ranging from $4 \%$ to $30 \%{ }^{4,10,13}$ However, in the present study the prevalence of precondylar process was only $2.48 \%$. This significant variation between these studies may be because of the regional differences in samples. Opinions concerning the etiology of precondylar tubercles differs; some investigators have considered them as 'developmental relics'14-16, while others have postulated them as ossification within the atlanto-occipital ligaments or as artificial deformation formed due to head binding. ${ }^{2,17}$ These enlarged paramedian bony masses ventral to the foramen may form a pseudojoint with the apical segment of the odontoid process or anterior arch of the atlas, thereby affecting the kinetic anatomy and integrity of the atlantooccipital articulation. ${ }^{18}$

The third occipital condyle, also known as condylustertius or median occipital condyle is described as a bony process in the median line located at the front rim of the occipital foramen magnum with an articular facet for the apex of the odontoid process or the anterior arch of the atlas. ${ }^{19}$ As this third occipital condyle lies in midsagital plane it may limit rotation of head. This type of variation is relatively rare. In the present study, we observed incidence of third occipital condyle $(0.5 \%)$ consistent with earlier findings. ${ }^{5,20}$ But this trait is more common in the Melanesian samples which was reported to be $5 \% .{ }^{10}$ The length of third occipital condyle $\left(2 \mathrm{~mm}\right.$ in this case) varies in the literature from $13-14 \mathrm{~mm} \cdot{ }^{21}$

Prebasioccipital arch also known as hypocondylar arch is a bony, bulging complete arch at the front rim of the occipital foramen magnum. In extremely rare cases, it can be isolated and mounted on the dens axis. Presence of prebasioccipital arch was observed in only two crania $(0.9 \%)$ of South African white ${ }^{5}$ and in the present study only one skull $(0.5 \%)$ had complete prebasioccipital arch. Presence of this arch may form a joint or pseudojoint with the odontoid process or the anterior arch of atlas and may lead to limitation in the range of motion of the CVJ.22 Due to formation of joint or pseudojoint with the odontoid process there is an increased prevalence of os odontoideum. ${ }^{18}$

Mobility and integrity of the atlanto-occipital articulation can get affected by bony masses ventral to foramen magnum in the form of tubercle or exostosis. This variant is due to ossification of the ligament of the odontoid process of the 
axis. ${ }^{23}$ The frequency of such tubercle varies from $0.47-$ $15 \%$ in the literature ${ }^{5,6,24}$ but present study showed $0.5 \%$ case which was $3 \mathrm{~mm}$ in length. In the literature length of the tubercles ranged from $0.5-7 \mathrm{~mm}$ with rounded or flat appearance. ${ }^{6,24}$ This wide range of frequency of these tubercles makes us think that this must be an epigenetic variation with a marked racial component. Such accessory vertebral elements along the anterior margin of foramen magnum may cause reduction of circumference of foramen magnum and may compress the spinal cord or pyramidal fibers.

Bassiocciputcleft is a rare variant observed in the basioccipital region. ${ }^{25}$ In a radiographic study,Lombardi observed this variation only in one out of 4000 patients $(0.025 \%) .{ }^{26}$ In the present study we observed one case of basioccipital cleft in 202 skulls studies $(0.5 \%)$ which is slightly higher than the previous studies. These clefts may be an important clue for finding other skull anomalies with which they are frequently associated like choanal atresia ${ }^{3}$ as formation of basiocciput and onset of oro-nasal communication occurs in a timerelated sequence manner. Therefore choanal anomalies, midline defects of hypophyseal cartilage (encephalocele) and basioccipital anomalies may share common factors of timing and etiology. ${ }^{3}$

Notch like defect in basiocciput is called as fossa navicularis (fossa navicularis magna, large pharyngeal fossa).The fossa navicularis lies anterior to the pharyngeal tubercle and the pharyngeal bursa. It lies close to the nasopharynx, the clivus and the sphenoidalsinuses. The prevalence of Fossa Navicularisin our study group was $1.49 \%$, which is in the range reported in the literature. ${ }^{27}$ Average dimensionsof fossa navicularisis 5 to $11 \mathrm{~mm}$ length, $3-4.5 \mathrm{~mm}$ width, and 3- $7 \mathrm{~mm}$ depth. ${ }^{28}$ But in present case the depth was much less compared to previous study. According to $\mathrm{Cankal}^{7}$ and his associates differential diagnosis of fossa navicularis includes Rathke's pouch cyst, adenoid retention cyst, adenoid hypertrophy, Tornwaldt's cyst, mucocele of sphenoidal sinus, dermoidteratoma of posterior nasopharyngeal wall.

\section{Conclusion}

Numerous anomalies in the region of the occipital bone are called "occipital dysplasies."Variants and deformities of the craniocervical junction comprise disturbances of segmentation, aplasies, hypoplasies, and dysraphic disturbances. These variations may be either asymptomatic or clinically manifest. Clinical manifestations develop only with advanced age or after a traumatic event. Symptoms can be manifested in the form of mechanical compression of vascular structure or nervous structure or marked rigidity or disturbance or mechanical mobility of skull joints. Therefore, morphological variations in the basiocciput region and its embryological basis are worth considering for the better diagnosis and treatment approaches for the diseases of this region.

\section{References:}

1. Williams PL, Warwick R, Dyson M, Bannister LH.Gray's Anatomy: Osteology chapter,The individual cranial bones. $37^{\text {th }}$ edition. Edinburgh: Churchill Livingstone, $1993: 373$

2. Oetteking B. On the morphological significance of certain craniovertebral variations. Anatomical Record1923; 25: 339-53.

\section{http://dx.doi.org/10.1002/ar.1090250605}

3. Johnson GF, Israel H. Basioccipital cleft. Radiology1979; 133:101-3.

4. Vasudeva N, Choudhry R. Precondylar tubercles on the basiocciput of adult human skulls. J Anat 1996; 188: 207-10.

5. Taitz C. Bony observations of some morphological variations and anomalies of the craniovertebral region. ClinAnat 2000; 13:354-60.

http://dx.doi.org/10.1002/1098-2353(2000)13:5<354::AIDCA5 $>3.0 . \mathrm{CO} ; 2-6$

6. Lakhtakia PK, Premsagar IC, Bisaria KK, et al. A tubercle at the anterior margin of foramen magnum. J Anat 1991; 177: 209- 10.

7. Cankal F, Ugur HC, Tekdemir I, et al. Fossa navicularis: anatomic variation at the skull base. ClinAnat 2004; 17:118-22.

http://dx.doi.org/10.1002/ca.10191

8. Figueiredo N, Moraes LB, Serra A, et al. Median (third) occipital condyle causing atlantoaxial instability and myelopathy. Arquivos de Neuro-Psiquiatria 2008; 66: 90-92. 2013

http://dx.doi.org/10.1590/S0004-282X2008000100023

9. Berry AC. Factors affecting the incidence of non-metrical skeletal variants. J Anat 1975; 120: 519-35.

10. Hanihara T, Ishida H. Frequency variations of discrete cranial traits in major human populations. III. Hyperostotic variations. J Anat 2001; 199:251-72.

\section{http://dx.doi.org/10.1046/j.1469-7580.2001.19930273.x}

11. Corruccini RS. An examination of the meaning of cranial discrete traits for human skeletal biological studies. Am J PhysAnthropol 1974;40:425-45. 


\section{http://dx.doi.org/10.1002/ajpa.1330400315}

12. Lahr MM. The Evolution of Modern Human Diversity. Cambridge: Cambridge University Press UK, 1996.

13. Gupta SC, Srivastava AK, Gupta CD, et al. Incidence of precondylar tubercle in crania of Uttar Pradesh. AnthropAnz1981; 39: 321-5.

14. Kollmann F. Varianten am osoccipitale, besonders in der umgebung des foramen occipitale magnum. Anatomischeranzeiger 1905;27:231-6.

15. Ingelmark BE. Uber das craniovertebraleGrenzgebietbeim Menschen. ActaAnat1947; 6:1-116.

16. Broman GE. Precondylar tubercles in American Whites and Negroes. American Journal of Physical Anthropology 1957; 15: 125-35. http://dx.doi.org/10.1002/ ajpa. 1330150114

17. Marshall D. Precondylar tubercle incidence rates. American Journal of Physical Anthropology1955; 13: 147-51.

http://dx.doi.org/10.1002/ajpa.1330130112

18. Van Gilder JC, Menezes AH, Dolan KD. The craniovertebral junction and its abnormalities. Futura, New York, 1987.

19. Shapiro R, Robinson F. Anomalies of the cranio-vertebral border. American Journal of Roentgenology 1976; 127: 281-7.

http://dx.doi.org/10.2214/ajr.127.2.281

20. Rao PV. Median (third) occipital condyle. ClinAnat 2002; 15:148-51.

\section{http://dx.doi.org/10.1002/ca.1111}

21. Hadley LA. Atlanto-occipital fusion, ossiculumterminale and occipital vertebra as related to basilar impression with neurological symptoms. Am J Roentgenol Radium Ther 1948; 59: 511-24.

22. Von Torklus D, Gehle W. The upper cervical spine. Grune\& Stratton, New York, 1972.

23. Tobias PV. The nasopharynx: review of structure and development, with notes on speech, pharyngeal hypophysis, chordoma and the dens. J Dent Assoc S Afr 1981;36:765-78.

24. Vazquez JF, Verona JA, Balbas JA, Porrero MG, Ayucar EB. Tubercle at the foramen magnum. Skull Base Surg 1996; 6: 169-70.

\section{http://dx.doi.org/10.1055/s-2008-1058641}

25. Kruyff E. Transverse cleft in the basi-occiput. ActaRadiolDiagn (Stockh). 1967; 6: 41-8.

26. Lombardi G. The occipital vertebra. Am J Roentgenol Radium TherNucl Med1961; 86: 260-9.

27. Beltramello A, Puppini G, El-Dalati G, Girelli M, Cerini R, Sbarbati A, Pacini P. fossanavicularis magna.Am J Neuroradiol 1998;19:1796-8.

28. Sullivan LR. The fossa pharyngeain American Indian crania. American Anthropologist 2009; 22:237-43.

http://dx.doi.org/10.1525/aa.1920.22.3.02a00030 